\title{
EFFECTS OF ZUMBA FITNESS PROGRAM ON BODY COMPOSITION OF WOMEN
}

\author{
Adriana Ljubojević1, Vladimir Jakovljević ${ }^{1}$, and Milijana Popržen ${ }^{2}$ \\ ${ }^{1}$ Faculty of Physical Education and Sport, University of Banjaluka, \\ Bosnia and Herzegovina \\ ${ }^{2}$ Fitness studio "Sport Trend", Banjaluka, Bosnia and Herzegovina
}

doi: 10.5550/sgia.141001.en.004L

ORIGINAL SCIENTIFIC PAPER

UDC: $793.3-055.2$

\section{SUMMARY}

The aim of this research was to determine the effects of zumba fitness program on changes of women body composition. 12 women aged 25-35 participated in the conducted research. The zumba fitness program was estimated after eight weeks of exercise, total of 24 training sessions. Body weight, fat percentage, fat mass, fat free mass and total body water were measured at the beginning and at the end of the research. The effects of fat-free training model were analyzed by using Paired sample $\mathrm{T}$ test. The obtained result showed that zumba fitness program achieved statistically significant improvement in total body weight loss $(p=.019)$, fat percentage $(p=.012)$ and fat free $(p=.000)$. Although the value of fat free mass $(0.22 \mathrm{~kg})$ and the total amount of body water $(0.15 \mathrm{~kg})$ recorded increase after completed program, they were not statistically significant. The study results clearly indicated that the zumba fitness exercise can be used as effective group fitness exercise for the change in body composition of women.

Key Words: body composition, effects of exercise, zumba fitness.

\section{INTRODUCTION}

Group fitness exercises represent the form of programmed physical activity to improve health and change body shape. The zumba fitness is a new kind of dance workout, inspired by Latin American music and Latin American dances. The exercise combines the basic of dance merengue, salsa, samba, cumbia, reggeaton and other Latin American dances, uses basic aerobic steps, but also enriches their composition of the other dance like hip-hop, belly dancing, Indian, African dance, etc. It is fusion of basic principles of aerobic interval training and strengthening exercises which promote consumption of calories, improve cardiovascular system and strength of the whole body (Perez \& Greenwood-Robinson, 2009). This modern approach of fitness exercising satisfies goals such as harmony of the body, improving posture and strengthening bone-joint segments of the locomotors apparatus (Furjan-Mandić, Kosalec, \& Vlašić, 2011). The researches confirm that the implementa- tion of various forms of group fitness program contributed to statistically significant effects in improving functional and motoric abilities of a woman (Mandarić, Sibinović, Mikalački, \& Stojiljković, 2011; Oreb, Matković, Vlašić, \& Kostić, 2007; Park, Park, Kwon, Yoon, \& Kim, 2003; Šebić, Šahat, Zuković, \& Lukić, 2012), and changes in women body composition, as well (Donges, Duffield, \& Drinkwater, 2010; Stasiulis, Mockiene, Vizbaraite, \& Mockus, 2010; Wong et al., 2002). Also, the latest researches separate dance aerobic as the most effective group fitness program (Hižnayova, 2013; Oreb, Matković, Vlašić, \& Kostić, 2007; Kostić, Đurašković, Miletić, \& Makalčki, 2006; Kostić \& Zagorc, 2005; Luettgen, Foster, Doberstein, Mikat, \& Porcari, 2012; Stoiljković, Mandarić, Todorović, \& Mitić, 2010; Viskic-Štalec, Štalec, Katić, Podvorac, \& Katović, 2007) which through motivating music implement creative choreography primarily aimed to entertain the trainees. The advantage of this model of exercise is that every practice is a new entertainment based on various dance steps with dif- 
ferent intensity and form of exercising, what makes the participants more motivated (Perez \& Greenwood-

-Robinson, 2009). This is very important from the aspect of maintaining interest for continuous exercise, since the main reason for leaving the group fitness program is monotony of each training session in long term of practicing (Stoiljković et al., 2010). What is the most effective group fitness program that include healthcare, aesthetic, social and entertainment character of exercising is the question that fitness instructors often ask themselves. The aim of this research is to reveal the effects of zumba fitness program on changes in women body composition.

\section{METHODS}

\section{Sample of participants and varibales}

The study was conducted on a sample of 12 women aged 25 to 35 who participated in all training sessions during eight weeks of implementation of zumba fitness program. During this research (April and May) they did not practice any other kind of physical exercises. They were tested before and after the implementation of zumba fitness program. Testing was performed in a sports hall of Faculty of Physical Education and Sport where the temperature was about $20^{\circ} \mathrm{C}$. All 24 zumba trainings were performed by a licensed zumba instructor. The basic descriptive statistic parameters were calculated for body weight (TM), fat percentage (FAT), fat mass (FATMASS), fat-free mass (FFM) and total body water (TBW).

\section{Zumba fitness program}

Zumba fitness exercise was perfomed three times per week in the evening. Each zumba training (60 minutes) contained basic principles of zumba excercise: warm-up, main part of the workout (zumba party section), cool down and streching (Perez \& Greenwood-Robinson, 2009). Exercise intensity is determined by the tempo of the music that changed during training sections. Warm up contained basic dance steps (march, step touch, side to side etc.) with gradually accelerating tempo of music (120-135 bpm), without leaps and jumps. In the second part of the warm-up the muscle toning exercises were performed with soft intensity through dance variations, slightly squats were allowed (tempo 125-140 bpm). The goal of warming up was to increase body temperature, muscle blood flow, joint mobilization and the psychological preparation, as well. Total warm-up time was 8-10 minutes (tempo 120-140 bpm). The main part of the zumba training was performed with 8-10 original zumba fitness songs. The dance choreogra- phies and movements intensity was created in accordance with tempo changing of music (tempo between 140-160 bpm). All Latin American dance choreographies (merengue, salsa, samba, belly dance, cha cha cha, tango etc.) with their differences in character and dynamics of movement (Lukić, 2006) provide dosing of exercise intensity. Each dance lasts 3-5 minutes, with pause of $15-30 \mathrm{sec}$. The aim of the main part of the training is that trainees enjoy the music and dance, and practice at the same time. Cool down as the final part of the training contained easy dance movement with soft music with mental and physical relaxing purpose. Stretching was performed for muscle relaxation, as also to prevent muscle soreness and increase body flexibility. There were not any jumps or squats allowed, and all the movements could be performed in standing, sitting or lying position (tempo of music $-100 \mathrm{bpm}$ ). When program was constructed it was considered that intensity of exercising can be changed according to previous adaptability. The intensity of exercise is dosed by using toning sticks (zumba toning program) as well as by changing character of the dance moves in presented choreographies.

\section{Measurement description}

All body parameters were measured by TANITA body analyzer BC-418MA III. Examinees were tested in sports equipment, barefoot, in womans' fitness pants and shirts. During the data collection they were standing on the bottom of body analyzer and held electrodes in both arms. Data input contains body height and age, and for the testing "standard" category was selected. Olso, data input containes weight equipment $(0.300 \mathrm{~g})$. After signal the direct current goes through the body and analyzes necessary body parameters.

\section{Data analysis}

Data gathered during this research were analyzed using statistic programs for personal computers IBM SPSS 20.0. for Windows. For analysis of basic statistic data and distribution of results on initial and final measurement, basic descriptive parameters were calculated: arithmetic mean, minimal value, maximal value, standard error mean, standard deviation and K-S test. The effects of applied training model were analyzed using Paired sample $\mathrm{T}$ test. The level of statistical significance was set at $p<.05$.

\section{RESULTS}

Descriptive statistics in Table 1 indicates changes of values in all tested parameters after eight weeks of 
zumba fitness program. On average, the body weight was reduced for $0.77 \mathrm{~kg}$, fat percentage for $1.05 \%$, fat mass for $1.01 \mathrm{~kg}$, fat-free mass (composed of muscle, bone, tissue, water and other non-fat mass) increased for $0.22 \mathrm{~kg}$, and total body water increased for $0.15 \mathrm{~kg}$. K-S test indicates a normal distribution of the obtained results.

Table 2 shows the effectiveness of applied zumba fitness program on changes in women body composition. The results indicate that there are statistically significant differences between initial and final mea- surements in parameters: body mass (.01), fat percentage (.01) and fat mass (.00). However, even the results shown in Table 1 indicate the increase of means in fat-free mass $(0.22 \mathrm{~kg})$ and total body water $(0.15 \mathrm{~kg})$, they did not show as statistically significant (FFM $p=.50$; TBW $p=.54)$.

\section{DISCUSSION}

Obviously, applied zumba fitness program has caused statistically significant changes in women body

TABLE 1

Results of descriptive parameters of initial and final body composition measurement.

\begin{tabular}{|c|c|c|c|c|c|c|c|c|}
\hline & & $n$ & $M$ & Min & $\operatorname{Max}$ & $S D$ & $S E$ & $K-S$ \\
\hline \multirow{5}{*}{$\begin{array}{l}\text { 岁 } \\
\text { 光 }\end{array}$} & TM & 12 & 66.85 & 59.10 & 83.60 & 8.30 & 2.39 & .47 \\
\hline & FAT & 12 & 30.05 & 24.90 & 38.70 & 4.59 & 1.32 & .77 \\
\hline & FATMASS & 12 & 20.83 & 15.20 & 32.40 & 5.49 & 1.58 & .57 \\
\hline & FFM & 12 & 46.48 & 43.40 & 56.10 & 3.74 & 1.08 & .49 \\
\hline & TBW & 12 & 34.03 & 31.80 & 41.10 & 2.74 & .79 & .47 \\
\hline \multirow{5}{*}{ 壳 } & TM & 12 & 66.08 & 58.20 & 83.50 & 8.35 & 2.41 & .63 \\
\hline & FAT & 12 & 29.00 & 24.00 & 36.70 & 4.08 & 1.17 & .37 \\
\hline & FATMASS & 12 & 19.37 & 13.90 & 30.60 & 4.90 & 1.41 & .64 \\
\hline & FFM & 12 & 46.70 & 43.50 & 58.40 & 4.46 & 1.28 & .23 \\
\hline & TBW & 12 & 34.18 & 31.80 & 42.80 & 3.28 & .94 & .24 \\
\hline
\end{tabular}

Legend: $\mathbf{n}$ - Number of respondents; M - Sample mean; Min - Minimum; Max - Maximum; SD - Standard deviation; SE - Standard error; K-S - Normality of the distribution of results; TM - Body mass; FAT - Fat percentage; FATMASS - Total fat mass; FFM

- Fat-free mass; TBW - Total body water.

TABLE 2

Effects of zumba fitness program exercise on body composition of women.

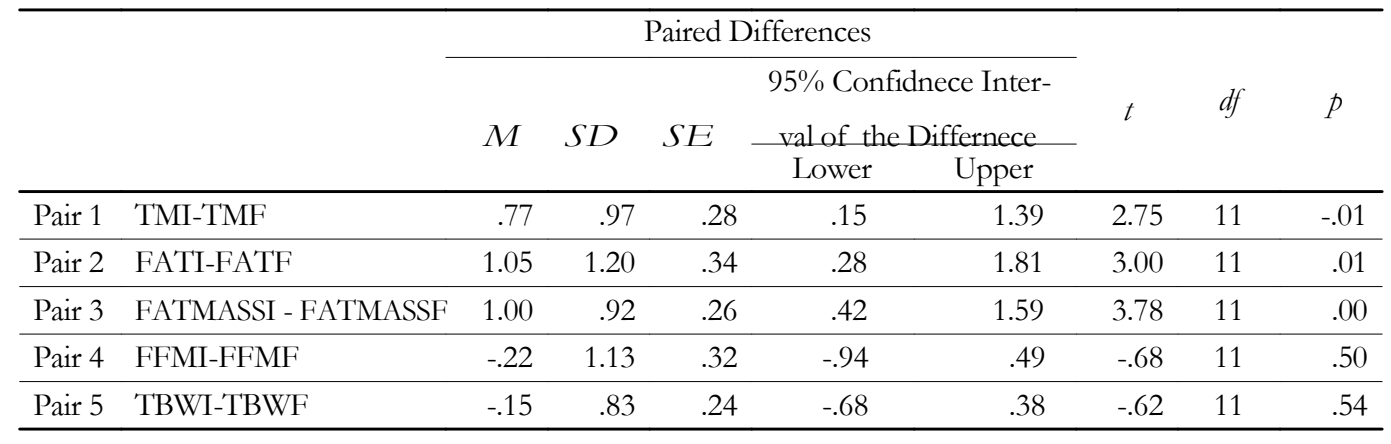

Legend: M - Sample mean; SD - Standard deviation; SE - Standard error; t - Students' t distribution; df - Degrees of freedom; p - Probability; TMI - Body mass initial; TMF

- Body mass final; FATI - Fat percentage initial; FATF - Fat percentage final; FATMASSI - Total fat mass initial; FATMASSF - Total fat mass final; FFMI - Free fat mass initial; FFMF - Free fat mass final; TBWI - Total body water initial; TBWI Total body water final. 
composition. The changes are reflected primarily on reduction of body mass ( $p=.01$ ), fat percentage $(p=.01)$ and fat mass $(p=.00)$. Applied zumba fitness program achieved the most effects on the fat percentage that has been reduced for $1.05 \%$, and the loss of body fat, in average $-1.01 \mathrm{~kg}$. Body weight was decreased on average for $0.77 \mathrm{~kg}$. Comparing zumba fitness workout with tae bo aerobics trainings Hižnayova (2013) examined differences in the intensity of exercise. The study was conducted on 11 women during 6 zumba trainings and 6 tae bo aerobic trainings. The heart rates were assessed in three parts of the training: after warm-up, after the main part of the training and after relaxation and stretching. The results show that the intensity of exercise during the warm-up and the main part of the training statistically significantly increased in all 6 zumba trainings compared to tae bo aerobic trainings $(p<.05)$. Energy consumption (measured in kilocalories) during all trainings was also significantly higher in favor of zumba fitness model exercise $(p<.01)$. Similar results were obtained in the studies of Barene, Krustrup, Jackman, Brekke, and Holtermann (2013) who investigated the effects of twelve-week zumba fitness program at the percentage of fat mass and the total amount of fat mass, in a sample of women employed in the health sector. They practised 2 to 3 hours a week. The results showed that the group that exercised zumba fitness reduced total body fat mass $(-0.6 \mathrm{~kg} ; p<.05)$ in comparison to the control group. In generally, zumba fitness training program outside of working hours can lead to certain health benefits for women employed in health care. The zumba fitness exercise, among other things, is based on the variety of zumba programs (zumba classic, zumba gold, zumba toning, zumba sentao, zumba kids, etc.) in which the complexity of dance choreographies and intensity of exercise are adapted to age and the goals that want to be achieved by practicing. In particular, it should be stressed that the conducted research on the effects of zumba fitness program in a relatively short time period of eight weeks caused a significant changes in the physical parameters of women, which is not negligible if we know that the most common motive of an individual to join the group fitness programs is the reduction of fat mass and weight loss.

\section{CONCLUSION}

The research of eight-week zumba fitness program on a sample of 12 women showed statistically significant effects on changes in body composition of women. They are reflected in the reduction of body weight, fat percentage and fat mass. Although, even if the value of fat free mass and total body water increased, they were not shown as statistically significant. The research showed high efficiency of zumba fitness training program on the reduction of body fat, which is very important since it is the common motive for joining group fitness programs. The uniqueness of zumba fitness exercising is in the variety of Latin dance choreographies and dynamic music that create an atmosphere of fun (zumba party) in which trainees forget they are practicing. This approach to exercise enables long-lasting interest and continuous exercising. It would be interesting to examine the effects of Zumba fitness program on the reduction of body fat of individual body segments observed over the long period and continuous exercise (at least $3 \mathrm{x}$ per week), or to compare the effectiveness of applying Zumba fitness program compared to the other group fitness programs. It should be noted that researches about the effects of zumba fitness exercise are rare compared to studies of other aerobic exercise. This is because the zumba fitness is the latest "hit" that appeared in the domain of aerobic exercise and that its actual effects on different populations and for different purposes are yet to be examined. This paper is a contribution to the clarification of its actual effectiveness in the changes of physical parameters of women.

\section{REFERENCES}

Barene, S., Krustrup, P., Jackman, S. R., Brekke, O. L., \& Holtermann, A. (2013). Do soccer and zumba exercise improve fitness and indicators of health among female hospital employees? A 12week RCT. Scandinavian Journal of Medicine \& Science in Sports on line. Retrived from http:// onlinelibrary.wiley.com/doi/10.1111/ sms.12138/full. doi: 10.1111/sms.12138

Donges ,C. E., Duffield, R., \& Drinkwater, E. J. (2010). Effects of resistance or aerobic exercise training on interleukin-6, C-reactive protein, and body composition. Medicine and Science in Sport and Exercise, 42(2), 304-413. doi: 10.1249/

MSS.0b013e3181b117ca; PMid: 20083961

Furjan-Mandić, G., Kosalec, V., \& Vlašić, J. (2011). The effects of aerobic exercise on the increase of repetitive strength in women. In S. Simović (Ed.), 3th International aspects of Sports, Physical education and Recreation (pp. 75-83). Banjaluka, Bosnia and Herzegovina: Faculty of Physical Education and Sport. doi: 10.5550/SP.3.2011.09 Hižnayova, K. (2013). Exercise intensity during zumba fitness and tae bo aerobics. Journal of 
Human Sport and Exercise, 8(2), S228-S241. doi: 10.4100/jhse.2012.8.Proc2.26

Kostić, R., Đurašković, R, Miletić, Đ., \& Makalački, M. (2006). Changes in cardiovascular fitness and body composition of women under the influence of dance aerobic. Facta Universitatis, 4(1), 59-71.

Kostić, R., \& Zagorc, M. (2005). Comparison of changes in cardiovascular fitness two models of aerobic exercise of women. Facta Universitatis, $3(1), 45-57$.

Lukić, A. (2006). Realcije iə̌među motorickih sposobnosti i efikasnosti iquodenja osnovnih elemenata tehnike u sportskom plesu [The relationship between motor skills and performance efficiency of the basic technique steps in sport dance]. Unpublished master's thesis. Universita of Banja Luka, Faculty of Physical Education and Sports.

Luettgen, M., Foster, C., Doberstein, S., Mikat, R., \& Porcari, J. (2012). Zumba: Is the "fitnessparty" a good workout? Journal of Sports Science and Medicine, 11(2), 357-358. PMid: 24137072; PMCid: PMC3737860

Mandarić, S., Sibinović, A., Mikalački, M., \& Stojiljković, S. (2011). The effects of the program HI-Low aerobics on morphological characteristics and functional ability students in the eight grade. Journal of Sports science and Health, 1(1), 18-23.

Oreb, G., Matković, B., Vlašić, J., \& Kostić, R. (2007). The structure of the functional abilities of the dancers. Croatian sports herald, 9(1), 16-23
Park, S. K., Park, J. H, Kwon, Y. C., Yoon, M. S., \& Kim, C. S. (2003). The effects of long-term aerobic exercise on maximal oxygen consumption, left ventricular function and serum lipids in elderly women. Journal of Physiological Anthropology and applied Human Science, 22(1), 11-17. doi: 10.2114/jpa.22.11; PMid: 12672978

Perez, B., \& Greenwood-Robinson, M. (2009). Zumba: Ditch the workout, join the party! The Zumba weight loss program. New York, NY: Maggie Greenwood-Robinson.

Stasiulis, A., Mockiene, A., Vizbaraite, D., and Mockus, P. (2010). Aerobic exercise-induced changes in body composition and blood lipids in young women. Medicine, 46(2), 129-134.

Stoiljković, S., Mandarić, S., Todorović, K., \& Mitić, D. (2010). The effects of "Omnibus" aerobics program on body composition of women. Physical Culture, 64(2), 59-67.

Šebić, L., Šahat, S., Zuković, A., \& Lukić, A. (2012). Coordination tests predictive value on success during the performance of dance and aerobics motion structures. Homosporticus, 14(1), 22-26.

Viskić-Štalec, N., Štalec, J., Katić, R, Podvorac, D., \& Katović, D. (2007). The impact of danceaerobic training on the morpho-motor status in female high-scholars. Collegium Antropologicum, 31(1), 259-266. PMid: 17598411

Received: March 13, 2014 Revision received: May 30, 2014 Accepted: Jun 23, 2014

Correspondence to: Adriana Ljubojevic, $\mathrm{PhD}$

Faculty of Physical Education and Sport University of Banja Luka

Bulevar Vojvode Petra Bojovića 1a 78000 Banja Luka

Bosnia and Herzegovina

Phone: +387 65567612

E mail: adri.ljubojevic@gmail.com 